\title{
Mecânica e microbiologia de placas produzidas a partir de osso cortical bovino, conservadas em diferentes meios
}

\author{
Mechanic and microbiology of plates produced from bovine cortical bone, conserved in several means
}

\author{
Edson Vilela de Melo Filho ${ }^{I}$ Ricardo Marius Della Lúcia ${ }^{I I}$ Ana Elisa Pato Salgado ${ }^{I}$ \\ Fernando Borges Miranda ${ }^{I}$ Manuela Aleluia Drago ${ }^{I}$ Marilda Onghero Taffarel ${ }^{I}$

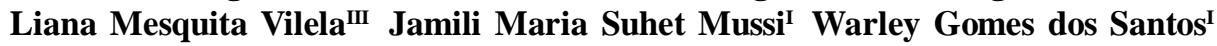 \\ Marcos Santos Zanini ${ }^{\mathrm{I}}$ Patricia Maria Coletto Freitas,
}

\section{RESUMO}

Objetivou-se com este trabalho avaliar a resistência mecânica de placas ósseas produzidas a partir de osso cortical bovino, conservadas em diferentes meios, e a eficiência desses meios em inibir o crescimento de microrganismos. Foram utilizadas 168 placas confeccionadas a partir de tíbia bovina e conservadas em glicerina a 98\%, solução salina a $150 \%$, solução de açúcar a 300\%, líquido de Dakin, congeladas em $N_{2} \mathrm{~L}$ a $-196^{\circ} \mathrm{C}$, ou esterilizadas em óxido de etileno. Após reidratação em solução de cloreto de sódio a $0,9 \%$ por seis horas, elas foram submetidas a ensaios mecânicos de tração, compressão, flexão e torção. Foi realizada avaliação microbiológica das placas anterior e imediatamente após a reidratação, com ou sem adição de enrofloxacina a 0,5\%. Não se observou diferença significativa $(P<0,01 \%) d a$ resistência ao ponto de ruptura entre as placas conservadas nos diferentes meios, congeladas-descongeladas ou esterilizadas. Micro-organismos foram isolados das placas conservadas em solução saturada de sal, açúcar, Dakin ou congeladas em $N_{2} L$, anterior e após a reidratação. Entretanto, após o uso da solução de cloreto de sódio 0,9\%, acrescida de enrofloxacina a $0,5 \%$, não foram isolados microrganismos. Portanto, placas de osso bovino, conservadas em solução saturada de açúcar ou sal, glicerina a 98\%, solução de Dakin, congeladas em $N_{2} L$ ou esterilizadas em óxido de etileno assemelham-se em relação à biomecânica e a reidratação com solução de cloreto de sódio a 0,9\%, acrescida de enrofloxacina a $0,5 \%$, é eficaz no controle do crescimento microbiano.
Palavras-chave: implantes, enxertos, biomateriais, meios de conservação, ensaios mecânicos.

\begin{abstract}
The objective of this study was to evaluate the mechanical strength of bone plates yielded from bovine cortical bone, conserved in different solutions, and the efficiency of these solutions in the inhibition of microorganism's growth. A hundred and sixty eight plates yielded from bovine tibiae were conserved in $98 \%$ glycerin, $150 \%$ saline solution, 300\% sugar solution, Dakin solution, frozen in $N_{2} L$ at $-196^{\circ} \mathrm{C}$, or sterilized in ethylene oxide gas. After rehydration in $\mathrm{NaCl} 0.9 \%$ solution for six hours, plates were subjected to tensile, compression, bending and twisting testing. The microbiological evaluation of bone plates was $s$ carried out before and immediately after rehydration, with or without enrofloxacin $0.5 \%$ addition. There was no significant difference $(P<0.01 \%)$ on resistance to the rupture point in plates conserved in different solutions, frozenthawed or sterilized. Microorganisms were isolated from plates conserved in satured salt solution, sugar satured solution, Dakin solution or frozen in $\mathrm{N}_{2} L$, before and after rehydraion However, after the use of $\mathrm{NaCl} 0.9 \%$ solution added of enrofloxacin $0.5 \%$, microorganisms were not isolated. Therefore, bovine bone plates conserved in sugar or salt satured solution, $98 \%$ glycerin, Dakin solution, frozen in $\mathrm{N}_{2} \mathrm{~L}$ or sterilized in ethylene oxide gas present similar biomechanical tests results, and rehydrated with a solution of $\mathrm{NaCl} 0.9 \%$ plus enrofloxacin $0.5 \%$ is effective on microorganism growth control.
\end{abstract}

Key words: implants, grafts, biomaterials, conservation solutions, mechanical testing.

'Departamento de Medicina Veterinária, Universidade Federal do Espírito Santo (UFES), Alegre, ES, Brasil.

"Laboratório de Propriedades da Madeira, Departamento de Engenharia Florestal, Universidade Federal de Viçosa (UFV), Viçosa, MG, Brasil.

IIIDepartamento de Medicina Veterinária, UFV, Viçosa, MG, Brasil.

${ }^{\mathrm{IV}}$ Departamento de Clínica e Cirurgia veterinárias, Universidade Federal de Minas Gerais (UFMG), 31.270-901, Belo Horizonte, MG, Brasil. E-mail: pcoletto@yahoo.com.br. Autor para correspondência. 


\section{INTRODUÇÃO}

A busca de biomateriais alternativos ao metal para confeccionar implantes cirúrgicos, como os polímeros biodegradáveis, a cerâmica e os derivados do óleo da mamona, vem ocorrendo devido ao fato de que alguns metais utilizados na confecção de próteses ortopédicas causem problemas de biocompatibilidade, osteointegração e possuam módulos de elasticidade acima do ideal (FISCHER-BRANDIES et al., 1992). Assim, o emprego de materiais produzidos a partir de osso bovino tem sido proposto na confecção de implantes como pinos, placas e parafusos, por poderem promover as mesmas funções de um enxerto ósseo, ou seja, serem osteoindutores e osteocondutores (STEVENSON, 1998).

Para a conservação desses biomateriais, têm sido utilizadas diversas substâncias, que, de acordo com MOTA et al. (2002), devem possuir alto poder estabilizador, impedindo a total decomposição dos tecidos e o crescimento de micro-organismos, além de preservar, ao máximo, a integridade celular e aumentar a resistência dos tecidos à tração.

Objetivou-se com esse estudo avaliar a resistência mecânica ao ponto de ruptura de placas produzidas a partir osso cortical bovino, conservadas em glicerina a $98 \%$, solução salina a $150 \%$; solução de açúcar a 300\%, líquido de Dakin, nitrogênio líquido e esterilizadas em óxido de etileno, bem como a eficiência desses meios de conservação relacionados ao crescimento de micro-organismos.

\section{MATERIAL E MÉTODOS}

Foram utilizadas para este estudo 168 placas, produzidas a partir de amostras de tíbias bovinas frescas, da porção médio-diafisária (sentido longitudinal), oriundas de abatedouro comercial, coletadas de forma não asséptica. As placas foram padronizadas com as seguintes dimensões: $6,0 \pm 0,4 \mathrm{~cm}$ de comprimento, $0,6 \pm 0,1 \mathrm{~cm}$ de largura e $0,3 \pm 0,1 \mathrm{~cm}$ de espessura (Figura 1A). Após usinagem, foram higienizadas em uma cuba contendo solução de cloreto de sódio a $0,9 \%$ e distribuídas em seis grupos de igual número, em que foram conservadas, a saber: 1) Grupo $\mathrm{Sal}(\mathrm{GS})(\mathrm{n}=28)$ - em recipiente de vidro estéril, contendo $600 \mathrm{~mL}$ de solução saturada de sal comercial $^{(a)}$, na proporção de 1,5g de sal para 1,0mL de água destilada; 2) Grupo Açúcar (GA) (n=28) - em recipiente de vidro estéril, contendo $600 \mathrm{~mL}$ de solução saturada de açúcar comercial $^{(b)}$, na proporção de $3,0 \mathrm{~g}$ de açúcar comercial para 1,0mL de água destilada; 3) Grupo Glicerina (GG) $(\mathrm{n}=28)$ - em recipiente de vidro estéril, contendo $600 \mathrm{~mL}$ de glicerina 98\% (c); 4) Grupo Dakin (GD) (n=28) - em recipiente de vidro estéril, contendo $600 \mathrm{~mL}$ de líquido de Dakin $^{(\mathrm{d})}$; 5) Grupo Nitrogênio Líquido (GN) (n=28) em botijão criogênico, contendo nitrogênio líquido à $196^{\circ} \mathrm{C}$; 6) Grupo Óxido de Etileno (GO) $(\mathrm{n}=28)$ esterilizadas em óxido de etileno ${ }^{(e)}$ e conservadas em temperatura ambiente, em embalagem asséptica.

Após o período de conservação de 45 dias, as placas foram submetidas a ensaios mecânicos destrutivos: tração, compressão, flexão e torção. Para cada um dos quatro tipos de ensaios mecânicos, utilizaram-se seis placas de osso bovino (corpos de prova) de cada grupo, previamente reidratadas por um período de seis horas, conforme descrito por SALBEGO \& RAISER (2006) e AMENDOLA (2007), em solução de cloreto de sódio a $0,9 \%$, na proporção de $40 \mathrm{~mL}$ de solução por placa. Anteriormente a cada ensaio, os corpos de prova foram mensurados em todas as suas dimensões com auxílio de um paquímetro digital.

Para os ensaios biomecânicos, utilizou-se uma máquina universal, eletromecânica, digital, com capacidade de 10T, da marca Pavitest/Contenco, com sistema computadorizado de aquisição, análise e saída de dados. Nos ensaios, avaliou-se a força máxima ao ponto de ruptura, definida como a força necessária para romper totalmente o corpo de prova, expressa em quilograma-força (kgf) ou um de seus múltiplos. A leitura dos valores das forças aplicadas foi realizada por meio do uso de célula de carga e a determinação das deformações realizada pelo deslocamento das barras do equipamento, as quais foram conectadas por um sistema de aquisição de dados controlados por computador, o qual permitiu o controle automatizado do sistema responsável pela coleta de dados e derivação das propriedades.

Para os ensaios de tração, utilizou-se uma célula de carga de 10T a uma velocidade constante de $1 \mathrm{~mm} \mathrm{~min}{ }^{-1}$. Os corpos de prova foram usinados seguindo um padrão normatizado para esse tipo de ensaio (Figura 1B). As extremidades dos corpos de prova foram fixadas às garras do equipamento no sentido longitudinal (Figura 1C). Os ensaios de compressão foram realizados com uma célula de carga de 10T e uma velocidade de $0,5 \mathrm{~mm} \mathrm{~min}^{-1}$. Os corpos de prova foram serrados, tendo seu comprimento reduzido para $2,0 \pm 0,2 \mathrm{~cm}$. As barras de compressão do equipamento foram alinhadas para impor carregamento uniaxial, na tentativa de eliminar os riscos de flambagem (Figura 1D). Os ensaios de flexão foram realizados em três pontos de apoio com uma célula de carga de 10T a uma velocidade de $0,5 \mathrm{~mm} \mathrm{~min}^{-1}$. Os corpos de prova foram colocados em plano horizontal, sendo apoiados 
em dois pontos sobre um suporte de ferro, acoplado à barra inferior do equipamento. $\mathrm{O}$ terceiro ponto foi fixado à barra superior do equipamento (Figura $1 \mathrm{E}) . \mathrm{O}$ ensaio de torção foi realizado com auxílio de um suporte de madeira preso à barra inferior da máquina. Esse suporte era constituído por dois pontos de fixação para encaixe do corpo de prova horizontalmente, sendo um fixo e outro móvel. O móvel foi preso a uma polia, fixada por um barbante e preso à barra superior da máquina (Figura 1F). Ao movimentar a barra superior da máquina de forma ascendente, a polia girava, realizando a rotação no corpo de prova. Utilizou-se para isso uma célula de carga de $250 \mathrm{~kg}$ e uma velocidade de $15 \mathrm{~mm} \mathrm{~min}^{-1}$.

Para a análise microbiológica qualitativa, duas placas ósseas foram removidas de cada meio conservante, de forma asséptica, no interior de capela de fluxo laminar. As placas foram lavadas, sucessivamente, com intervalos de 5 minutos, em três tubos tipo Falcon, estéreis, contendo $35 \mathrm{~mL}$ de solução de cloreto de sódio a 0,9\%. Após a terceira lavagem, uma placa óssea foi colocada em um tubo de ensaio com tampa contendo tioglicolato e outra em tubo de ensaio com tampa contendo BHI caldo (Brain Heart Infusion - Infusão de cérebro e coração). Foram realizadas leituras a cada seis horas durante 48 horas, para verificar a ausência ou presença de turvação dos meios de crescimento, correspondente à ausência ou presença de micro-organismos, respectivamente. Para análise microbiológica quantitativa, foram removidas, no interior da capela de fluxo laminar, duas placas ósseas

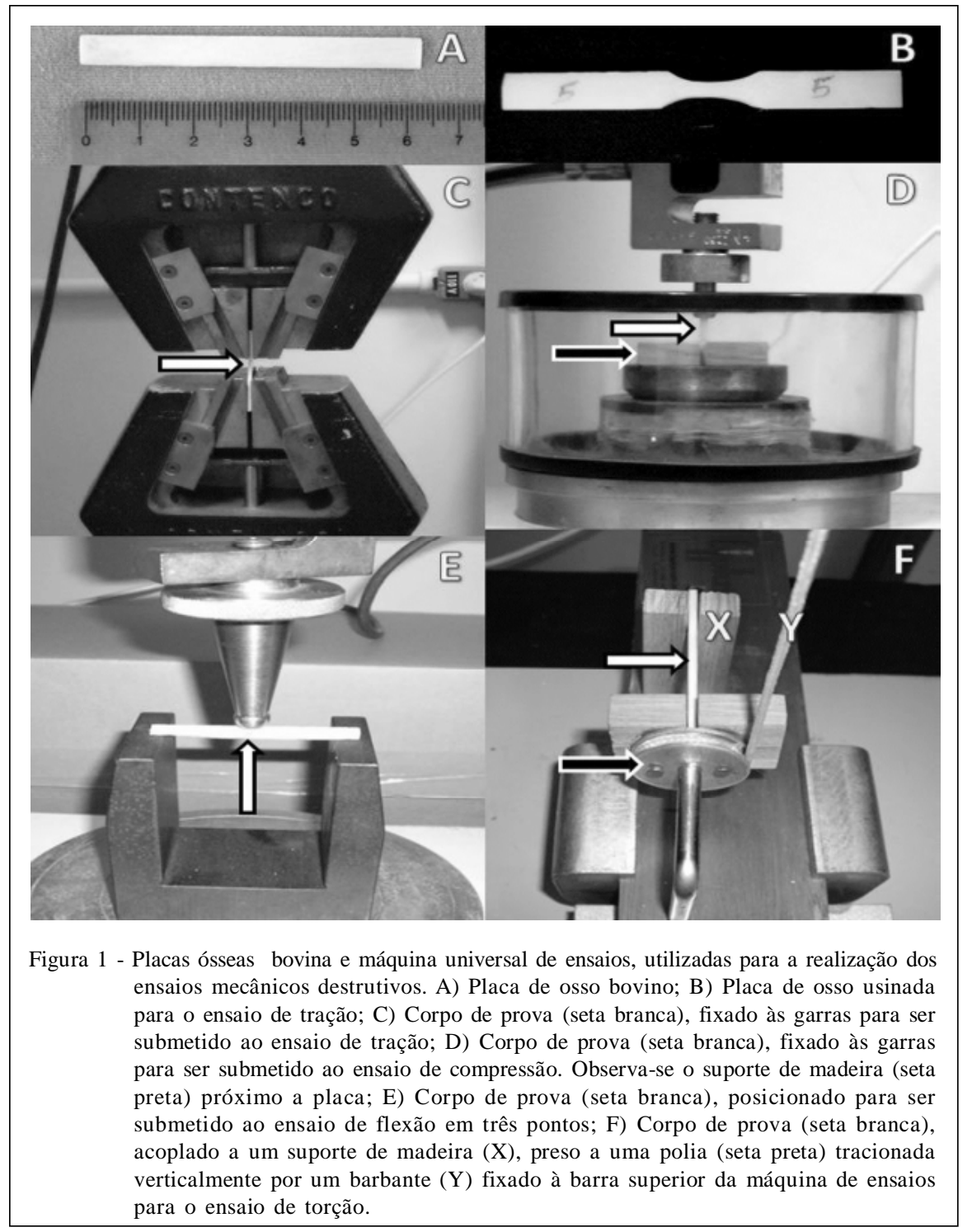

Ciência Rural, v.41, n.4, abr, 2011. 
de cada meio conservante, sendo, para cada grupo, uma acondicionada em recipiente individual de vidro, estéril, com tampa, contendo $100 \mathrm{~mL}$ de solução de cloreto de sódio a $0,9 \%$ e a outra em solução de antibiótico (enrofloxacina a $0,5 \%{ }^{(\mathrm{f})}$ ) de igual volume, as quais haviam permanecido durante seis horas para reidratação. Após, 100 microlitros da solução utilizada para reidratação foram espalhados com auxílio de alças de Drigalsky em quatro placas de Petri, contendo: 1) BHI Ágar e cultivada em aerobiose, em estufa a $37^{\circ} \mathrm{C}$; 2) BHI Ágar e cultivada em anaerobiose, em estufa a $37^{\circ} \mathrm{C}$; 3) Ágar Sabouraud e cultivada à temperatura ambiente; 4) Ágar Sabouraud e cultivada em estufa a $37^{\circ} \mathrm{C}$. Foram realizadas leituras a cada 24 horas; durante 48 horas nas placas de Petri contendo BHI Ágar; e a cada 24 horas, durante 14 dias, nas placas de Petri contendo Ágar Sabouraud.

Para a análise estatística, as variáveis quantitativas foram submetidas à análise de variância (ANOVA). Quando apresentaram significância no nível de $1 \%$, foram realizados os testes de Duncan ou de Tuckey, conforme a instabilidade da variável.

\section{RESULTADOS E DISCUSSÃO}

Ao se avaliar o ponto de ruptura óssea, ao aplicar o teste de torção, não se observou diferença significativa $(\mathrm{P}<0,01)$ entre os grupos (solução saturada de sal, solução saturada de açúcar, glicerina a 98\%, líquido de Dakin, nitrogênio líquido e esterilização por óxido de etileno) (Error! Reference source not found.). Também não se encontrou, nos ossos conservados, nenhum tipo de microfissura, como o relatado por MELO et al. (1998), após conservarem osso de cão em glicerina a 98\%, e por HAJE et al. (2007), após esterilizacão por óxido de etileno de parafusos de osso bovino. Esse fato provavelmente ocorreu neste estudo devido à reidratação dos ossos antes da avaliação biomecânica, pois, de acordo com SALBEGO \& RAISER (2006), esse procedimento pode fazer com que ossos conservados voltem a apresentar características mecânicas semelhantes às de ossos frescos. Além disso, a padronização da coleta com relação à região óssea (porção médio-diafisária) contribuiu para diminuir as diferenças nos parâmetros ósseos, como o de cisalhamento, já que, segundo COWIN (1989), esse fator promove influência nos ensaios mecânicos, pois o osso é material visco elástico heterogêneo e anisotrópico.

Nos ensaios de compressão, não foram encontradas diferenças significativas entre os grupos $(\mathrm{P}<0,01)$ (Tabela 1). Esse resultado é diferente do observado por VOLPON \& COSTA (2000), que relataram maior resistência ao teste de compressão de osso córtico-esponjoso do homem, esterilizado em óxido de etileno, quando comparado ao osso conservado sob congelamento em freezer a $-14^{\circ} \mathrm{C}$. Também DELCARLO et al. (2007) relataram que ossos de cães conservados em glicerina apresentam menor resistência à compressão. Provavelmente, a reidratação pelo tempo de seis horas, recomendada por SALBEGO \& RAISER (2006) e AMENDOLA (2007), antes do referido teste, tenha proporcionado aos ossos conservados em óxido de etileno e glicerina um aumento na resistência à compressão, tornando-os semelhantes estatisticamente aos demais grupos. Além disso, o procedimento cauteloso no preparo dos corpos de prova, juntamente com o alinhamento das barras de compressão, como recomendado por GIBSON et al. (2008), nos momentos dos testes, aumentou a acurácia axial, pois contribuiu para uma distribuição homogênia da tensão.

Com relação ao teste de flexão, não se observou neste estudo diferença entre os grupos $(\mathrm{P}<0,01)$ (Tabela 1), verificando assim grau de rigidez óssea semelhante após conservação nos meios estudados. Discordando dos achados de HOFMANN et al. (2003), os quais, após estudarem pinos confeccionados a partir de ossos corticais de tíbias bovinas e esterilizados com óxido de etileno, autoclavagem e radiação gama, verificaram que os tratados com óxido de etileno apresentaram diminuição no grau de rigidez. $\mathrm{O}$ resultado deste estudo ocorreu provavelmente pelo fato dos meios conservantes atuarem de forma similar nas propriedades mecânicas do osso, ou seja, na sua fase mineral, mas especificamente na água. Assim, supõe-se que a glicerina a 98\%, a solução saturada de sal e açúcar, e a esterilização por óxido de etileno desidrataram o osso, promovendo assim um efeito protetor nas fibras ósseas. Em adição, o procedimento de se confeccionar o corpo de prova no sentido longitudinal de suas fibras, colaborou para se obter um resultado padronizado.

Nos ensaios de tração, não foram encontradas diferenças significativas $(\mathrm{P}<0,01)$ entre os tratamentos. Esse resultado discorda do relatado por SAMPAIO et al. (2009), que, após avaliar a força de micro-tração de ossos corticais de coelhos, verificaram que ossos conservados em nitrogênio líquido e líquido de Dakin apresentaram-se superior neste teste com relação aos conservados em glicerina a $98 \%$. Entretanto, neste estudo os ossos foram hidratados, diferentemente do estudo de SAMPAIO et al. (2009), o que justificou os resultados encontrados, pois, de acordo com CURREY (1988), a reidratação dos ossos restaura o módulo de elasticidade deles.

Ciência Rural, v.41, n.4, abr, 2011. 
Tabela 1 - Valores médios (kgf $\mathrm{cm}^{-2}$ ) e desvios padrão de ossos bovinos conservados em solução saturada de sal (GS) e açúcar (GA), glicerina (GG), Dakin (GD), nitrogênio líquido (GN) e óxido de etileno (GO), submetidos aos ensaios mecânicos de tração, compressão, flexão e torção.

\begin{tabular}{ccccc}
\hline & Tração & Compressão & Flexão & Torção $^{\text {a }}$ \\
\hline GS & $1047,3 \pm 201,9^{\text {a }}$ & $899,9 \pm 137,3^{\mathrm{b}}$ & $2125,5 \pm 224,8^{\mathrm{c}}$ & $875,4 \pm 114,1^{\mathrm{d}}$ \\
GA & $1304,7 \pm 158,8^{\mathrm{a}}$ & $954,4 \pm 127,7^{\mathrm{b}}$ & $2227,8 \pm 202,0^{\mathrm{c}}$ & $979,7 \pm 148,8^{\mathrm{d}}$ \\
GG & $1131,6 \pm 210,2^{\mathrm{a}}$ & $1025,3 \pm 169,5^{\mathrm{b}}$ & $2142,1 \pm 216,8^{\mathrm{c}}$ & $819,3 \pm 145,8^{\mathrm{d}}$ \\
GD & $1062,0 \pm 368,5^{\mathrm{a}}$ & $848,9 \pm 161,2^{\mathrm{b}}$ & $1916,4 \pm 143,5^{\mathrm{c}}$ & $891,4 \pm 37,6^{\mathrm{d}}$ \\
GN & $1144,8 \pm 65,4^{\mathrm{a}}$ & $836,4 \pm 102,1^{\mathrm{b}}$ & $2033,1 \pm 154,2^{\mathrm{c}}$ & $899,2^{\mathrm{a}} \pm 88,5^{\mathrm{d}}$ \\
GO & $926,2 \pm 170,0^{\mathrm{a}}$ & $846,8 \pm 121,5^{\mathrm{b}}$ & $1940,1 \pm 171,0^{\mathrm{c}}$ & $839,9 \pm 154,1^{\mathrm{d}}$ \\
\hline
\end{tabular}

Médias e desvio padrão seguidos de letras minúsculas na mesma coluna não diferem entre si ao nível de significância de $1 \%$, pelo teste de Duncan ou de Tuckey.

Na avaliação microbiológica, verificou-se a presença de Staphylococcus sp. nas placas ósseas conservadas em solução saturada de sal (GS), anteriormente e após a reidratação em solução de cloreto de sódio a $0,9 \%$. Entretanto, após reidratá-las com solução de cloreto de sódio a $0,9 \%$, acrescida de antibiótico enrofloxacina a $0,5 \%$, não se verificou a presença desses micro-organismos. Concordando com o descrito por FREITAS (2006), que não observou sinal de bactérias ou infecção após enxertar peritônio bovino, conservado em solução saturada de sal e reidratado em solução de cloreto de sódio a $0,9 \%$, acrescida de enrofloxacina, em tendão calcanear de coelhos. A presença de bactérias encontradas nas placas conservadas em solução de sal provavelmente foi decorrente da contaminação do osso durante a coleta e principalmente na usinagem.

$\mathrm{Na}$ avaliação microbiológica das placas conservadas em açúcar a 300\% (GA), encontrou-se presença de fungo anterior e após a reidratação com solução de cloreto de sódio. Entretanto, após a reidratação com solução acrescida de antibiótico, não foram observados mais esses micro-organismos. Entretanto, segundo PRATA et al. (2001), essa solução promove o aumento da pressão osmótica do meio, criando condições desfavoráveis à reprodução e crescimento de várias bactérias, fungos e leveduras. A presença de fungo nas placas deste estudo possivelmente foi decorrente do excesso de manuseio aplicado sobre elas, anteriormente a sua colocação no meio conservante.

Com relação às placas ósseas conservadas em glicerina (GG), observou-se presença de Bacillus spp. Coccus spp. antes da reidratação. Concordando com o relatado por RANDI et al. (2002), que descreveram que a glicerina apresenta propriedade antisséptica, atuando como bactericida e fungicida, exceto contra formas esporuladas. Entretanto, após a reidratação das placas sem antibiótico, não se notou a presença desses micro-organismos. Isso se deveu provavelmente ao uso da solução de cloreto de sódio a $0,9 \%$, que promoveu a diluição da amostra retirada do meio conservante, juntamente com a baixa quantidade desse micro-organismo no meio. Nesse sentido, de acordo com AMENDOLA (2007), a glicerina diminui de forma significativa a quantidade de microorganismos em amostras contaminadas.

As placas ósseas do grupo Dakin (GD) apresentaram presença de Staphylococcus sp. antes e após a reidratação com solução de cloreto de sódio a $0,9 \%$ sem antibiótico. O crescimento desse microorganismo deveu-se ao fato de os ossos terem sido conversados no Dakin em temperatura ambiente. De acordo com CUNNINGHAN et al. (1980) e PÉCORA et al. (1987), a solução de Dakin é bactericida, porém sua meia-vida é curta quando ela é aquecida a $37^{\circ} \mathrm{C}$ ou armazenada em temperatura ambiente, devido ao fato de ocorrer diminuição da concentração de cloro no produto.

Nas placas ósseas conservadas em nitrogênio líquido (GN), observou-se a presença de Staphylococcus sp. antes e após a reidratação sem antibiótico. Concordando com os achados de SOUZA et al. (2006) que, ao avaliarem microbiologicamente sêmen de caprinos criopreservados em nitrogênio líquido, verificaram que na pós-descongelação, a bactéria do gênero Staphylococcus spp. estava presente na maioria das amostras. Isso provavelmente deveu-se ao fato de a coleta e usinagem das placas ósseas terem sido realizadas de forma não asséptica, e o nitrogênio líquido não ter sido eficiente como meio bactericida.

As análises microbiológicas antes e após a reidratação dos ossos conservados esterilizados em óxido de etileno (GO) não revelaram a presença de micro-organismos. Esse resultado deveu-se à eficiência 
do processo de esterilização por esse agente, pois, de acordo com POSSARI (2003), o óxido de etileno causa alquilação de compostos no interior dos microorganismos, principalmente a guanina e a adenina, presente no DNA.

\section{CONCLUSÃO}

Pode-se concluir que: ossos de bovinos conservados nos meios de solução saturada de açúcar e sal, glicerina a $98 \%$, óxido de etileno, Dakin e nitrogênio líquido, após reidratação em solução de cloreto de sódio a $0,9 \%$ por seis horas, assemelham-se em relação à biomecânica; e a reidratação com solução de cloreto de sódio a $0,9 \%$, acrescida de enrofloxacina a $0,5 \%$, é eficaz no controle de micro-organismos.

\section{FONTES DE AQUISIÇÃO}

a - Sal Cisne, Refinaria Nacional de Sal S.A., Cabo Frio, RJ. b - Açúcar Refinado União, Usina União e Indústria S.A., Recife, PE.

c - Glicerina, Labsynth Produtos Químicos para Laboratório LTDA, Diadema, SP.

d - Líquido de Dakin, Biodinâmica Química e Farmacêutica LTDA, Ibiporã, PR.

e - Acecil Vet Esterilização de Produtos Veterinários LTDA, Campinas, SP.

f - Baytril 10\%, Bayer. - São Paulo, SP.

\section{REFERÊNCIAS}

AMENDOLA, G.F. Aspectos biomecânicos, bacteriológicos e micológicos de diáfises femorais caninas conservadas em glicerina a $98 \%$ ou mel. 2007. 100f. Tese (Doutorado em Medicina Veterinária) - Universidade Federal de Santa Maria, Santa Maria, RS.

COWIN, S.C. "The mechanical properties of cortical bone tissue". In: 1989. p. $97-127$.

CUNNINGHAN, W.T. et al. Effect of temperature on the bactericidal action of sodium hypochlorite endodontic irrigant. Oral Surgery, Oral Medicine, Oral Pathology, v.50, n.6, p.569-571, 1980. Disponível em: <http://www.sciencedirect.com/ science?_ob=ArticleURL\&_udi=B 7GHR-4FT YGF4 M1\&_user=687358\&_coverDate $=12 \% 2 \mathrm{~F} 31 \% 2 \mathrm{~F} 1980 \& \_$rdoc $=1 \&$ _fmt=high\&_orig=gateway\&_origin=gateway\&_sort=d\&_docanch or $=\&$ view $=$ c\&_searchStrId $=1658725925 \& \_$rerunOrigin $=$google \&_acct $=$ C000037899\&_version $=1 \& \_u r l$ Version $=0$ \&_userid $=687358$ $\& \mathrm{md} 5=30309 \mathrm{dca} 66 \mathrm{aa} 5 \mathrm{bd} 684013 \mathrm{c} 719 \mathrm{bd} 805 \mathrm{~b} 0 \&$ searchtype $=\mathrm{a}>$. doi:10.1016/0030-4220(80)90443-0.

CURREY, J.D. The effects of drying and re-wetting on some mechanical properties of cortical bone. Journal of biomechanics, v.21, n.5, p.439-441, 1988.

DEL CARLO, R.J. et al. Integração de aloenxertos ósseos corticais associados ou não à células-tronco da medula óssea, proteína óssea morfogenética (BMP) e autoenxerto esponjoso em cães. Veterinária e Zootecnia, v.14, p. 204-215, 2007.
Disponível em: <http://www.fmvz.unesp.br/revista/volumes/ vol14_n2/Revista\%20v14n02_2007_66_77.pdf >. Acesso em: 24 fev. 2010.

FISCHER-BRANDIES, E. et al. Zum nacheis von titan im organismus bei temporärer Alloplastik. Deutsche Zahnärztliche Zeitschrift, v.47, p.526-528, 1992.

FREITAS, P.M.C. Eletroacupuntura no reparo do tendão calcanear comum em coelhos após enxertia com peritônio bovino. 2006. 92f. Tese (Doutorado em Medicina Veterinária) - Universidade Estadual Paulista, Jaboticabal, SP.

GIBSON, T.W.G. et al. The biomechanical properties of the feline femur. Veterinary and Comparative Orthopaedics and Traumatology, v.21, p.1-6, 2008. Disponível em: <http:/ /www.schattauer.de/en/magazine/subject-areas/journals-a-z/vcot/ contents/archive/issue/132/manuscript/9487.html>. Acesso em: 21 mar. 2010. doi: 10.3415/VCOT-07-08-0077.

HAJE, D.P. et al. Efeitos do processamento químico, da esterilização em óxido de etileno e da usinagem em parafusos de osso bovino: estudo com microscopia eletrônica de varredura. Revista Brasileira de Ortopedia, v.42, n.4, p.120-124, 2007. Disponível em: 〈http://www.rbo.org.br/pdf/abr_2007_06.pdf〉. Acesso em: 24 fev. 2010.

HOFMANN, C. et al. Influence of processing and sterilization on the mechanical properties of pins made from bovine cortical bone. Der Unfallchirurg, v.6, n.106, p.478-482, 2003. Disponível em: <http://www.springerlink.com/content/xcmb84x6rh4ymgvm/>. Acesso em: 13 fev. 2010. doi: 10.1007/s00113-003-0611-z.

MELO, E.G. et al. Aloenxerto ósseo cortical: avaliação do seu emprego em tíbia de cão. Arquivo Brasileiro de Medicina Veterinária e Zootecnia, v.50, n.4, p.385-394, 1998.

MOTA, F.C.D. et al. Análise ultra-estrutural da túnica muscular do intestino delgado de cães preservado em diferentes meios. Brazilian Journal of Veterinary Research and Animal Science, v.39, n.1, p.13-17, 2002. Disponível em: <http:// www.scielo.br/scielo.php? script $=$ sci_arttext\&pid $=$ S14 13 $95962002000100002 \& \operatorname{lng}=e n \& n r m=i s o>$. Acesso em: $24 \mathrm{fev}$. 2010. doi: $10.1590 / \mathrm{S} 1413-95962002000100002$.

PRATA, L.F; FUKUDA, R.T. Fundamentos de higiene e inspeção de carnes. Jaboticabal: Funep. 2001. 349p.

PÉCORA, J.D. et al. Estudo sobre o "shelf-life" da solução de Dakin. Revista de Odontologia da Universidade de São Paulo, v.1, n.1, p.4-7, 1987. Disponível em: <http:// www.forp.usp.br/restauradora/Trabalhos/shelf.html>. Acesso em: 24 fev. 2010.

POSSARI, J.F. Esterilização por óxido de etileno. São Paulo: Iátria, 2003. 136p.

RANDI, F.E. et al. Aplicabilidade e métodos de conservação de próteses biológicas. Unimar Ciências, v.11, n.1-2, p.39-44, 2002.

SALBEGO, F.Z. RAISER, A.G. Teste de resistência biomecânica de implantes ósseos corticais conservados em glicerina a $98 \%$ e submetidos a diferentes tempos de reidratação. In: CONGRESSO DO COLÉGIO BRASILEIRO DE CIRURGIA E ANESTESIOLOGIA VETERINÁRIA, 7., 2006, Santos, SP. 
Anais... Belo Horizonte: Arquivo Brasileiro de Medicina Veterinária e Zootecnia, 2006. V.58, supl, p.77-78, 2006.

SAMPAIO, R.S. et al. Variação da força de resistência à micro-tração de fragmentos de ossos corticais preservados em diversos meios e a fresco: estudo experimental em coelhos. Pesquisa Veterinária Brasileira, v.29, n.4, p.345-352, 2009. Disponível em: <http://www.scielo.br/ scielo.php? script=sci_arttext\&pid=S $0100-$ $736 X 2009000400012 \& \operatorname{lng}=e n \& n r m=i s o>$. Acesso em: 24 fev. 2010. doi: 10.1590/S0100-736X2009000400012.

SOUZA, A.F. et al. Avaliação microbiológica do sêmen fresco e congelado de reprodutores caprinos. Brazilian Journal of
Veterinary Research and Animal Science, v.43, n.3, p. 329336, 2006. Disponível em: <http://www.revistasusp.sibi.usp.br/ scielo.php ? script =sci_arttext \& pid=S $1413-$ 95962006000300006\&lng=pt\&nrm=iso>. Acesso em: 07 abr. 2010.

STEVENSON, S. Enxertos ósseos. In: SLATTER, D. Manual de cirurgia de pequenos animais. 2.ed. São Paulo: Manole, 1998. Cap.127, p.1014-1030.

VOLPON, J.B.; DA COSTA, R.M.P. Ensaio mecânico e uso clínico do enxerto homógeno processado. Revista Brasileira de Ortopedia, v.35, p.219-224, 2000. Disponível em: <http:// www.rbo.org.br/pdf/2000_jun_or09.pdf>. Acesso em: 24 fev. 2010. 